\title{
Far caudally migrated extraforaminal lumbosacral disc herniation treated by a microsurgical lateral extraforaminal transmuscular approach: case report
}

\author{
Anja Tschugg, MD, ${ }^{1}$ Sebastian Tschugg, MD, ${ }^{2}$ Sebastian Hartmann, MD, ${ }^{1}$ Paul Rhomberg, MD, ${ }^{3}$ and \\ Claudius Thomé, MD1 \\ 1Department of Neurosurgery and ${ }^{3}$ Department of Neuroradiology, Medical University of Innsbruck; and 2Department of Trauma \\ Surgery, Hospital Kufstein, Austria
}

\begin{abstract}
A 33-year-old man presented with moderate low-back pain and L-5 radiculopathy that progressed to severe paresis of L-5. On initial imaging, a corresponding spinal lesion was overlooked. Further CT and contrast-enhanced MRI demonstrated a presacral mass along the L-5 root far extraforaminally. A herniated disc was suspected, but with standard imaging a schwannoma could not be ruled out. The presacral L-5 root was explored via a microsurgical lateral extraforaminal transmuscular approach. To the best of the authors' knowledge, there have been no reports of sequestered extraforaminal lumbosacral disc herniations that herniated into the presacral region.
\end{abstract}

http://thejns.org/doi/abs/10.3171/2015.7.SPINE15342

KEY WORDS far-lateral disc herniation; extraforaminal disc herniation; extraforaminal transmuscular approach; sequestrectomy; far-out syndrome; lumbar

$\mathrm{C}$ OMPRESSING the exiting root with its dorsal ganglion, extraforaminal disc herniations (EFDHs) present with lancinating leg pain, whereas low-back pain is often moderate. These rare lesions may be difficult to detect if displaced far caudally to the presacral course of the L-5 root, but they have to be considered in the differential diagnosis of L-5 radiculopathy., 3,714 Currently, both $\mathrm{CT}$ and MRI deliver detailed preoperative imaging of the lumbar spine. ${ }^{3}$ EFDH can be treated via a microsurgical lateral extraforaminal transmuscular approach. ${ }^{4,9,13,16}$

\section{Case Report}

The patient has provided informed consent for the submission of this case report and for submission to the Journal of Neurosurgery: Spine.

\section{History and Examination}

A 33-year-old man presented to our outpatient clinic with moderate low-back pain that was assigned a visual analog scale (VAS) score of 3 and right-sided L-5 radiculopathy with a VAS score of 5 that progressed to severe paresis of L-5. Preoperative clinical examination demonstrated a $3 / 5$ paresis of the musculus extensor hallucis lon- gus, a $3 / 5$ paresis of the musculus tibialis anterior, a $4 / 5$ paresis of the musculus gluteus medius on the right side, hypesthesia in the L-5 dermatome, and normal reflexes. In an MRI study of the lumbar spine, a presacral lesion was overlooked at first, and the MR image seemed without evidence of nerve root compression. The patient had neither a relevant medical history nor a history of injury or recent travel. He reported some tick bites without anular rash that had occurred several months earlier. A spinal tap and a serological examination excluded the diagnosis of Lyme disease. A psychogenic paresis was assumed. After an interdisciplinary discussion, CT scanning and contrastenhanced MRI of the lumbar spine were performed. A lesion was detected in front of the sacrum along the presacral course of the L-5 nerve root (Fig. 1). A herniated disc was suspected, but a schwannoma could not be ruled out. Sequestered disc fragments were then diagnosed during surgery.

\section{Operation}

Surgery was performed after induction of general endotracheal anesthesia and with the assistance of an operating microscope (Pentero, Carl Zeiss Co.) with the patient 

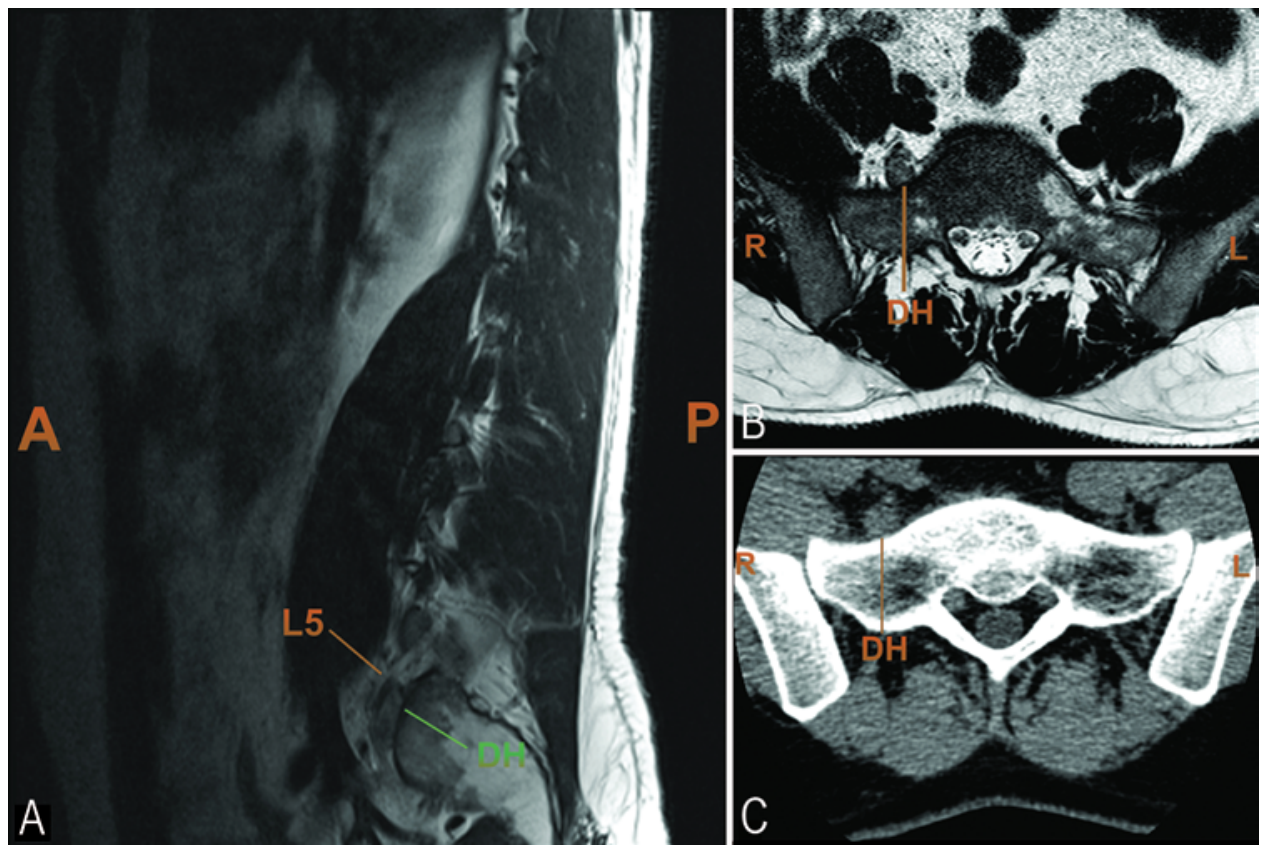

FIG. 1. Preoperative right parasagittal T2-weighted MRI sequence (A) showing a presacral hypointense lesion just beneath the L-5 root. Axial T2-weighted MRI sequence $(B)$ and axial CT scan $(C)$ demonstrating a right-sided presacral disc herniation $(\mathrm{DH}) . A=$ anterior; $L=$ left; $P=$ posterior; $R=$ right. Figure is available in color online only.

in a prone position. Lateral radiographs were obtained to determine the correct level for exposure. After a skin incision was performed $4.5 \mathrm{~cm}$ lateral to the midline on the ipsilateral side of the disc herniation, a minimally invasive dilatory retractor system (Spotlight, DePuy Synthes) was inserted. Muscle fibers were coagulated and cut. The L5S1 facet joint was identified and the location of the lumbosacral neuroforamen was confirmed by radiography. The retractor was repositioned more caudally centered in the ridge of the sacral ala. A cranial portion of the sacral ala was removed by a high-speed drill to approach the presacral part of the L-5 root (Fig. 2). The root ganglion was displaced laterally, and excessive manipulation was avoided. A large piece of solid disc material was identified caudally to the L-5 nerve root, carefully dissected, and then removed (Fig. 3). Hemostasis of the operative field was achieved. The thoracolumbar fascia and subcutaneous tissue were sutured separately, whereas the skin was closed with glue.

\section{Postoperative Course}

A postoperative contrast-enhanced MRI study showed adequate decompression of the L-5 nerve root (Fig. 4). Low-back pain completely disappeared postoperatively, whereas neuropathic leg pain of VAS Score 8 with allodynia persisted. The neurological condition was almost unchanged. The patient was discharged 5 days after the operation. He participated in an intense rehabilitation program 6 weeks thereafter. One year later an examination revealed no motor, sensory, or reflex abnormalities, and neuropathic leg pain disappeared completely.

\section{Discussion}

We report on a far extraforaminal lumbosacral herni- ated disc in the presacral region that was initially missed on standard imaging. Despite the introduction of high-resolution MRI, some disc fragments can be missed and mistaken for benign neoplasms. ${ }^{3,6}$ As in our patient's mass, atypically sequestered disc herniations usually appear heterogeneous, with hypo- to isointense signal on T1-weighted MRI and hypo- to hyperintense signal on T2-weighted MRI, depending on the time of occurrence. Contrastenhanced MRI rarely shows central enhancement of the herniated disc fragment, but a slight diffuse or peripheral rim can be observed. ${ }^{3}$ According to the literature, it is possible to detect this rare lesion with $3 \mathrm{D} \mathrm{MRI}{ }^{2}$ and to differentiate a suspected schwannoma with diffusion-weighted MR neurography, ${ }_{15}^{15}$ but this is not routinely performed in patients with radiculopathy.

A psychogenic neurological symptom is estimated to be present in approximately $9 \%$ of all patients seen in neurological practice, and is assumed if no morphological explanation is found. ${ }^{8}$ To provide the best chance for the patient's full neurological recovery, it is, however, essential to achieve an accurate diagnosis. This can be facilitated by thorough examination and interdisciplinary discussion. A microsurgical posterolateral transmuscular approach was then used that enables an excellent exposure of the extraforaminal compartment. This approach requires bone resection (usually limited to hypertrophied facets), which can increase the risk of future spinal instability. ${ }^{5,12,16}$ The first prospective randomized study was published in 2008 and showed significantly less pain medication in patients treated via a transmuscular approach. ${ }^{1}$ With adequate removal of the sacral ala, the presacral area can be reached easily. ${ }^{11,14}$

In a recently published retrospective study, sensory deficits in EFDH were unchanged in 31.2\% and improved in $51.4 \%$ of cases postoperatively. Similar results were 

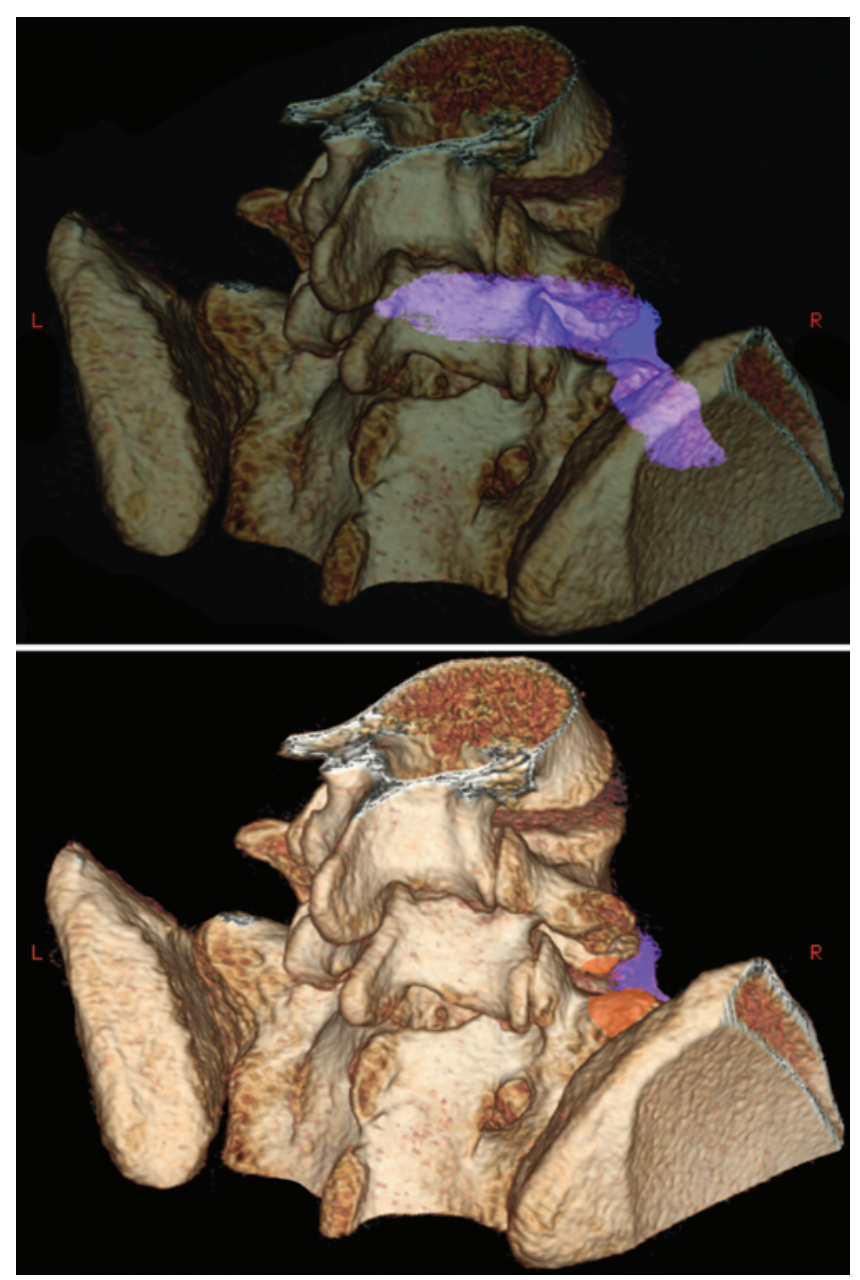

FIG. 2. Upper: Preoperative 3D CT reconstruction image showing a presacral disc herniation (violet). Lower: A cranial portion of the sacral ala was removed (red). Figure is available in color online only.

applied to motor deficits in a short-term follow-up of 6 weeks. In the long-term follow-up, 56.3\% reported complete relief of symptoms, whereas $42.5 \%$ of cases suffered from sensory deficits and $25.3 \%$ from weakness. ${ }^{10}$ Our patient suffered from neuropathic pain initially. Recovery of neurological function was slow. Preoperative diagnosis is

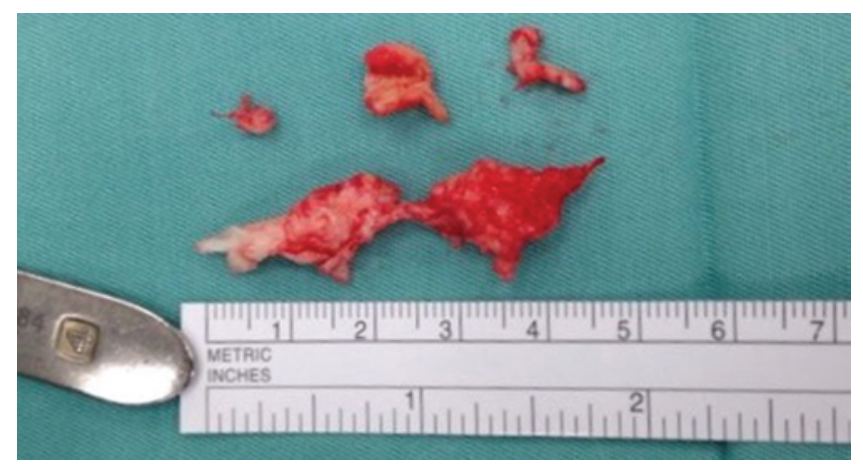

FIG. 3. Photograph showing a large disc fragment that was removed. Figure is available in color online only.

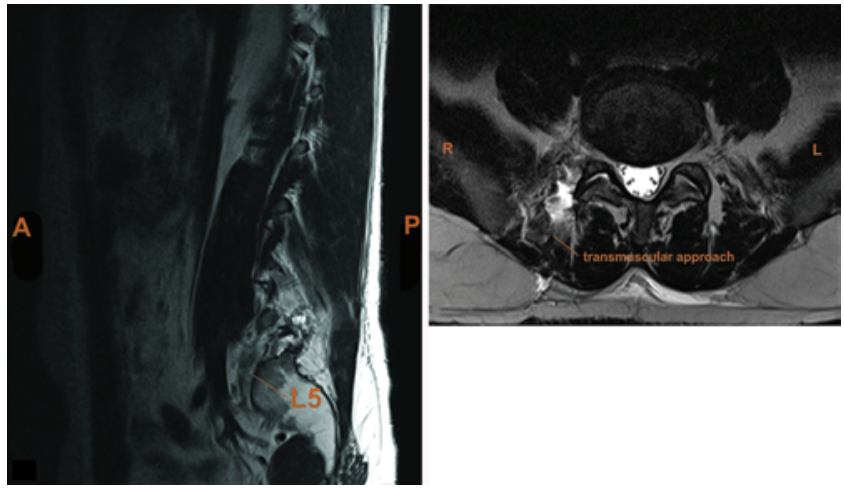

FIG. 4. Left: Postoperative right parasagittal T2-weighted MRI sequence demonstrating a decompressed L-5 root. Right: A lateral extraforaminal transmuscular approach was used. Figure is available in color online only.

thought to be very significant in the prevention of postoperative neurological deficits, but correct preoperative diagnosis in EFDH can be difficult. Careful imaging of the extraforaminal area is thus recommended routinely, especially if no intraspinal finding corresponds to the clinical presentation.

\section{References}

1. Brock M, Kunkel P, Papavero L: Lumbar microdiscectomy: subperiosteal versus transmuscular approach and influence on the early postoperative analgesic consumption. Eur Spine J 17:518-522, 2008

2. Byun WM, Kim JW, Lee JK: Differentiation between symptomatic and asymptomatic extraforaminal stenosis in lumbosacral transitional vertebra: role of three-dimensional magnetic resonance lumbosacral radiculography. Korean J Radiol 13:403-411, 2012

3. Carvi y Nievas MN, Hoellerhage HG: Unusual sequestered disc fragments simulating spinal tumors and other spaceoccupying lesions. Clinical article. J Neurosurg Spine 11:42-48, 2009

4. Eicker SO, Rhee S, Steiger HJ, Herdmann J, Floeth FW: Transtubular microsurgical approach to treating extraforaminal lumbar disc herniations. Neurosurg Focus 35(2):E1, 2013

5. Epstein NE: Foraminal and far lateral lumbar disc herniations: surgical alternatives and outcome measures. Spinal Cord 40:491-500, 2002

6. Karavelioglu E, Eser O: Intraradicular lumbar disc herniation in a rare localization: case report. Clin Neurol Neurosurg 115:232-234, 2013

7. Kikuchi K, Abe E, Miyakoshi N, Kobayashi T, Abe T, Hongo $\mathrm{M}$, et al: Anterior decompression for far-out syndrome below a transitional vertebra: a report of two cases. Spine J 13:e21e25, 2013

8. Lempert T, Dieterich M, Huppert D, Brandt T: Psychogenic disorders in neurology: frequency and clinical spectrum. Acta Neurol Scand 82:335-340, 1990

9. Madhok R, Kanter AS: Extreme-lateral, minimally invasive, transpsoas approach for the treatment of far-lateral lumbar disc herniation. J Neurosurg Spine 12:347-350, 2010

10. Marquardt G, Bruder M, Theuss S, Setzer M, Seifert V: Ultra-long-term outcome of surgically treated far-lateral, extraforaminal lumbar disc herniations: a single-center series. Eur Spine J 21:660-665, 2012 
11. Matsumoto $\mathrm{M}$, Watanabe $\mathrm{K}$, Ishii $\mathrm{K}$, Tsuji $\mathrm{T}$, Takaishi $\mathrm{H}$, Nakamura M, et al: Posterior decompression surgery for extraforaminal entrapment of the fifth lumbar spinal nerve at the lumbosacral junction. J Neurosurg Spine 12:72-81, 2010

12. Ozveren MF, Bilge T, Barut S, Eras M: Combined approach for far-lateral lumbar disc herniation. Neurol Med Chir (Tokyo) 44:118-123, 2004 (Tokyo)

13. Pirris SM, Dhall S, Mummaneni PV, Kanter AS: Minimally invasive approach to extraforaminal disc herniations at the lumbosacral junction using an operating microscope: case series and review of the literature. Neurosurg Focus 25(2):E10, 2008

14. Sasaki M, Aoki M, Matsumoto K, Tsuruzono K, Akiyama C, Yoshimine T: Middle-term surgical outcomes of microscopic posterior decompression for far-out syndrome. J Neurol Surg A Cent Eur Neurosurg 75:79-83, 2014

15. Takahara T, Hendrikse J, Kwee TC, Yamashita T, Van Cauteren M, Polders D, et al: Diffusion-weighted MR neurography of the sacral plexus with unidirectional motion probing gradients. Eur Radiol 20:1221-1226, 2010

16. Tessitore E, de Tribolet N: Far-lateral lumbar disc herniation: the microsurgical transmuscular approach. Neurosurgery 54:939-942, 2004

\section{Disclosures}

The authors report no conflict of interest concerning the materials or methods used in this study or the findings specified in this paper.

\section{Author Contributions}

Conception and design: A Tschugg. Acquisition of data: $\mathrm{S}$ Tschugg. Drafting the article: A Tschugg, S Tschugg, Hartmann, Rhomberg. Critically revising the article: Rhomberg, Thomé. Reviewed submitted version of manuscript: all authors. Approved the final version of the manuscript on behalf of all authors: A Tschugg. Administrative/technical/material support: A Tschugg. Study supervision: Thomé.

\section{Correspondence}

Anja Tschugg, Department of Neurosurgery, Medical University of Innsbruck, Anichstr. 35, Innsbruck A-6020, Austria. email: anja.tschugg@i-med.ac.at. 